\title{
Parietal foramen: incidence and topography
}

\author{
J. Naidoo®, J.S. Luckrajh®, L. Lazarus® \\ Department of Clinical Anatomy, School of Laboratory Medicine and Medical Sciences, College of Health Sciences, \\ University of KwaZulu-Natal, Westville Campus, Durban, South Africa
}

[Received: 27 June 2019; Accepted: 22 August 2019; Early publication date: 24 November 2020]

\begin{abstract}
Background: The parietal foramen (PF) is a small inconsistent aperture located at the border of the middle $1 / 3$ and posterior 1/3 of the parietal bone near the sagittal suture and is considered an emissary foramen. Cranial emissary foramina are of utmost importance due to the structures that traverse the foramen. Variations in these foramina are common. Knowledge of the PF is important when performing neurosurgical procedures as the emissary vessels are at risk.

Materials and methods: The present study used 100 dry adult calvaria to determine the frequency of PF, the diameter of the PF, as well as topography of the PF (using the sagittal suture as an anatomical landmark).

Results: A total of $32 \%$ of calvaria had PF present bilaterally; whilst 35\% of calvaria had unilateral PF. The study also reports $5 \%$ calvaria in which PF were present on the sagittal suture. The mean diameter recorded was $1.55 \mathrm{~mm}(0.74-3.08 \mathrm{~mm})$, and the mean distance between the lateral margin of the PF and the sagittal suture was $9.02 \mathrm{~mm}(4.44-18.20 \mathrm{~mm})$.

Conclusions: Knowledge of the incidence and topography of the PF may aid neurosurgeons in creating and adjusting techniques and procedures in order to mitigate the risk of injury to emissary veins and other structures emerging from the PF. (Folia Morphol 2021; 80, 4: 980-984)
\end{abstract}

Key words: parietal foramen, emissary foramen, osteology, incidence, topography, diameter, sagittal suture

\section{INTRODUCTION}

The parietal foramen (PF) is a small inconsistent opening located near the sagittal suture in the posterior part of the parietal bone [13]. This area is described as the obelion due to the representation of the Greek symbol obelos (\%) which depicts the PF on either side of the sagittal suture $[7,8]$.

When present, the PF transmits an emissary vein and is therefore considered one of the emissary foramina of the cranium [7]. Emissary veins drain the neurocranium as well as cephalic structures, and the parietal emissary veins connect the scalp veins with the superior sagittal sinus $[8,14]$. Emissary foramina also share an important relationship with the diploic veins of the skull, which may act as a pathway for the spread of infections from the extracranial veins to the intracranial sinuses [16].

No satisfactory explanation regarding the function of the PF has been reported, besides the transmission of vessels; therefore, the function of the PF remains unclear and under investigation $[1,14]$. Due to advancements in radiological techniques, information pertaining to skull foraminal size and symmetry has become increasingly important in the diagnosis of pathological conditions surrounding these foramina $[2,16]$.

Address for correspondence: Dr. L. Lazarus, Department of Clinical Anatomy, School of Laboratory Medicine and Medical Sciences, College of Health Sciences, University of KwaZulu-Natal, Westville Campus, Durban, South Africa, e-mail: ramsaroopl@ukzn.ac.za

This article is available in open access under Creative Common Attribution-Non-Commercial-No Derivatives 4.0 International (CC BY-NC-ND 4.0) license, allowing to download articles and share them with others as long as they credit the authors and the publisher, but without permission to change them in any way or use them commercially. 
Table 1. Incidence of the presence of the parietal foramen

\begin{tabular}{lccc}
\hline Author (year) [REF.] & Country & Sample size (n) & Incidence (\%) \\
\hline Boyd (1930) [4] & Scotland & 1500 & 60 \\
Berry and Berry (1967) [3] & Egypt & 250 & 44.2 \\
& Nigeria & 56 & 59.2 \\
& Palestine (Lachish) & 54 & 35.2 \\
& Palestine (Modern) & 18 & 22.2 \\
& India & 53 & 50 \\
& Burma & 51 & 50 \\
& North America & 50 & 62 \\
Keskil et al. (2003) [9] & Peru & 53 & 53 \\
Wysocki et al. (2006) [18] & Turkey & 200 & 63 \\
Yoshioko et al. (2006) [20] & Poland & 100 & 60 \\
Mann et al. (2009) [11] & USA & 20 & 50 \\
Debbarma et al. (2015) [6] & Japan & 137 & 80.3 \\
Gangmei et al. (2018) [7] & India & 40 & 43.8 \\
Weighted mean & India & 48 & 77.1 \\
Present study (2019) & - & - & $\mathbf{5 8 . 5}$ \\
\hline
\end{tabular}

Knowledge of the PF is imperative to neurosurgical perspectives since the emissary veins may be ruptured during surgery $[14,16]$. Bleeding from emissary veins may then result in the formation of a postoperative epidural haematoma [12].

The aim of the study was to investigate the anatomy of the PF with the objective of recording incidence, diameter, and topography of the PF in relation to the sagittal suture.

\section{MATERIALS AND METHODS}

A total of 100 adult calvaria were obtained from the Department of Clinical Anatomy, University of KwaZulu-Natal, South Africa. These calvaria were analysed to record the incidence and diameter of the PF. Furthermore, the distance of the PF from the sagittal suture was taken as a horizontal line from the midpoint of the sagittal suture to the lateral margin of the PF. Institutional ethical clearance was obtained from the Biomedical Research Ethics Committee (BE124/19).

A digital calliper (Linear Tools 2012, 0-150 mm, LIN 86500963) was employed to take measurements; these measurements were taken 3 times to ensure accuracy.

Exclusion criteria include: calvaria in which the parietal bone was damaged, and the distance of the foramina could not be recorded due to feint sagittal suture were excluded from the study.
Inclusion criteria include: calvaria without damage to the parietal bone and visible sagittal sutures were included in the study.

\section{RESULTS}

\section{Incidence}

The PF was found to be present in $68 \%$ of calvaria (Table 1 ) and $32 \%$ of calvaria displayed a bilateral presence of the PF. A total of $35 \%$ of calvaria had PF present unilaterally (right: $17 \%$, left: $18 \%$ ). The present study also reports $5 \%$ of calvaria which had PF present on the sagittal suture (Table 2).

\section{Topography}

The distance between the midpoint of the sagittal suture and the lateral margin of the PF, in the present study, was found to range between 4.44-18.20 mm, with a mean distance of $9.02 \mathrm{~mm}$ (Table 3).

\section{Diameter}

The present study recorded a mean diameter of $1.55 \mathrm{~mm}$, with a range of $0.74-3.08 \mathrm{~mm}$ (Table 4).

\section{DISCUSSION AND CONCLUSIONS}

The PF are generally found bilaterally at the junction of the middle $1 / 3$ and posterior $1 / 3$ of the parietal bone near the sagittal suture [7, 14, 19]. Margins of the PF are sharply defined enabling the radiologist to 
Table 2. Incidence of the topographical location of the parietal foramen

\begin{tabular}{lcccccc}
\hline Author (year) [REF] & Country & $\begin{array}{c}\text { Sample size } \\
\text { (n) }\end{array}$ & $\begin{array}{c}\text { Present bilaterally } \\
(\%)\end{array}$ & $\begin{array}{c}\text { Present unilaterally } \\
(\%)\end{array}$ & $\begin{array}{c}\text { Present on sagittal } \\
\text { suture (\%) }\end{array}$ & $\begin{array}{c}\text { Absent bilaterally } \\
\text { (\%) }\end{array}$ \\
\hline Boyd (1930) [4] & Scotland & 1500 & 19.9 & 25.9 & - & 39.6 \\
Berge and Bergman (2001) [2] & USA & 100 & 40 & 30 & - & 20 \\
Keskil et al. (2003) [9] & Turkey & 200 & 27 & 31 & 5 & - \\
Yoshioko et al. (2006) [20] & USA & 20 & 40 & 20 & 5 & 40 \\
Mann et al. (2009) [11] & Japan & 137 & 45.3 & 34.3 & 29.7 & 19.7 \\
Singh and Raibagkar (2011) [17] & India & 103 & 51 & -29 & 20 \\
Debbarma et al. (2015) [6] & India & 40 & 30 & 13.75 & - & 42.50 \\
Murlimanju et al. (2015) [14] & India & 58 & 55.20 & 32.70 & 3.40 & 12.10 \\
Gangmei et al. (2018) [7] & India & 48 & 62.50 & 29.20 & - & 8.30 \\
Weighted mean & - & - & $\mathbf{4 1 . 2}$ & $\mathbf{2 9 . 9}$ & $\mathbf{3 . 4}$ & $\mathbf{2 0 . 5}$ \\
Present study (2019) & South Africa & $\mathbf{1 0 0}$ & $\mathbf{3 2}$ & $\mathbf{3 5}$ & $\mathbf{5}$ & $\mathbf{3 2}$ \\
\hline
\end{tabular}

Table 3. Topography of the parietal foramen from the sagittal suture

\begin{tabular}{lcccc}
\hline Author (year) [REF.] & Country & Sample size & \multicolumn{2}{c}{ Distance from sagittal suture [mm] } \\
\cline { 4 - 5 } & & & Range & Mean \\
\hline Yoshioko et al. (2006) [20] & USA & 20 & $3.00-12.00$ & 8.00 \\
Pereira et al. (2013) [15] & Brazil & 31 & - & 7.9 \\
Murlimanju et al. (2015) [14] & India & 58 & $0.50-15.00$ & 6.70 \\
Halagatti and Sagar (2018) [8] & India & 215 & - & 6.60 \\
Shantharam and Manjunath (2018) [16] & India & 78 & - & 7.34 \\
Weighted mean & - & - & - & $\mathbf{6 . 9}$ \\
Present study (2019) & South Africa & $\mathbf{1 0 0}$ & $\mathbf{4 . 4 4 - 1 8 . 2 0}$ & $\mathbf{9 . 0 2}$ \\
\hline
\end{tabular}

Table 4. Size of the parietal foramen

\begin{tabular}{lcccc}
\hline Author (year) [REF] & Country & Sample size & \multicolumn{2}{c}{ Diameter [mm] } \\
\cline { 4 - 5 } & & & Range & Mean \\
\hline Berge and Bergman (2001) [2] & USA & 100 & - & 0.67 \\
Yoshioko et al. (2006) [20] & USA & 20 & $0.40-4.30$ & 1.80 \\
Collipal et al. (2009) [5] & Chile & 39 & $0.37-2.65$ & - \\
Mann et al. (2009) [11] & Japan & 110 & $1.80-2.00$ & - \\
Singh and Raibagkar (2011) [17] & India & 103 & - & 0.91 \\
Shantharam and Manjunath (2018) [16] & India & 78 & $0.86-5.57$ & - \\
Weighted mean & - & - & - & $\mathbf{0 . 8 8}$ \\
Present study (2019) & South Africa & $\mathbf{1 0 0}$ & $\mathbf{0 . 7 4 - 3 . 0 8}$ & $\mathbf{1 . 5 5}$ \\
\hline
\end{tabular}

differentiate between these foramina and other burr holes, caused by neurosurgical procedures, which are larger in size than that of the PF $[14,16]$.

Calvaria are formed by intramembranous ossification with the parietal bone forming via two ossification centres, located on either side of the midline, which eventually fuse $[1,19]$. The formation of the
PF, occurring initially as a single defect, is due to the prolonged ossification of the posterior parietal region of the skull leading to a 'V-shaped' notch known as the third fontanelle, or pars obelica $[1,7]$. Thus, the defect persists as a small or oval foramen and the formation of the unilateral or bilateral foramina occurs as the third fontanelle closes [1, 14]. 


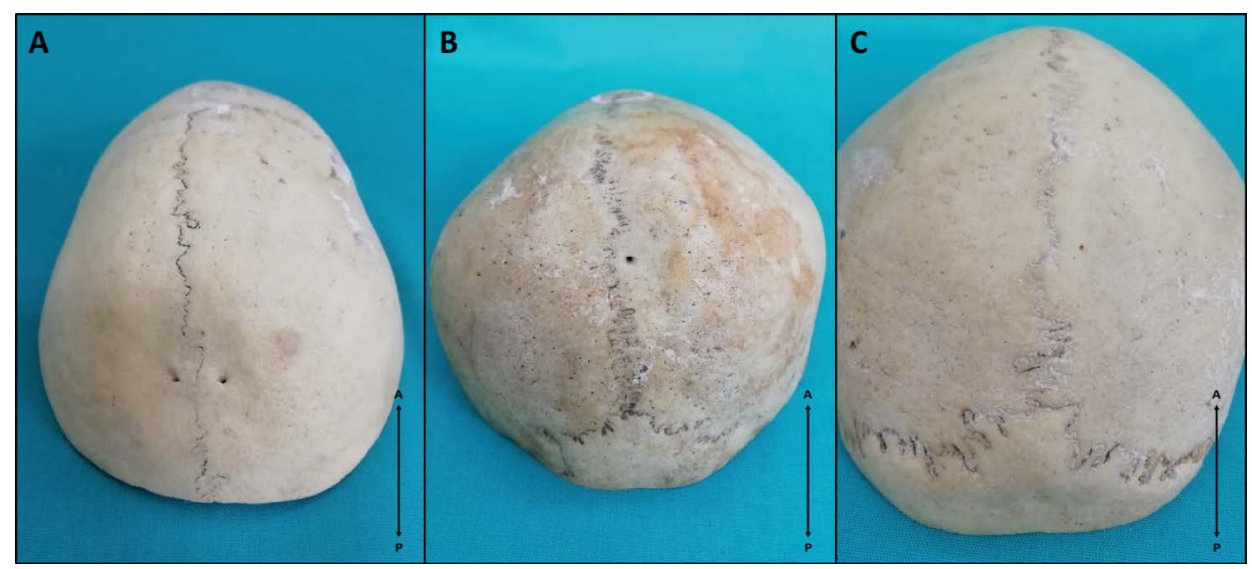

Figure 1. Calvaria depicting incidence of parietal foramen (PF); A. PF present bilaterally; B. PF present unilaterally; C. PF absent bilaterally.

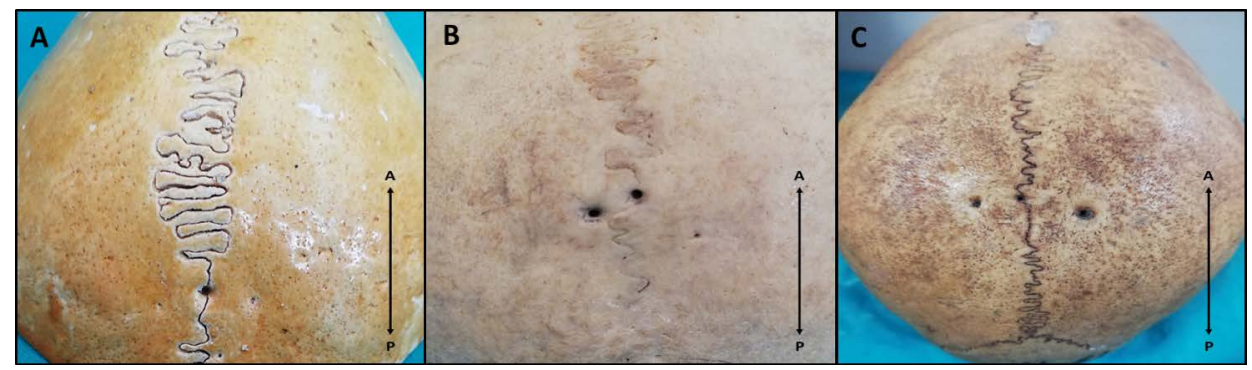

Figure 2. Calvaria depicting presence of median parietal foramen (PF); A. Median PF; B. Median PF with unilateral PF; C. Median PF with bilateral PF.

The identification of emissary foramina, such as the $\mathrm{PF}$, is imperative for the understanding of regional vessels and to distinguish between these foramina and variant anatomy [14]. The present study recorded the incidence of PF in $68 \%$ of cases which concurs with the literature reviewed, which recorded a weighted mean incidence of $58.5 \%$ (Table 1). Makandar et al. [10] stated that the incidence of the PF is a standard phenomenon - this statement concurs with the high incidence found in the present study.

This study reports a $32 \%$ occurrence of bilateral PF which is similar to the findings of Debbarma et al. [6] (30\%); however, this finding is lower than those of Murlimanju et al. [14] (55.2\%) and Gangmei et al. [7] $(62.5 \%)$ (Fig. 1A, Table 2). The weighted mean incidence of bilateral PF in the literature is $41.2 \%$ (Table 2).

A review of the literature revealed a weighted mean incidence of unilateral PF as $29.9 \%$ (Table 2). This finding correlates with that of the present study which recorded unilateral PF in 35\% (right: 17\%, left: $18 \%$ ) of cases (Fig. 1B, Table 2). The finding of the present study correlates closely with that of Berge and Bergman [2] (30\%) and Murlimanju et al. [14]
(32.7\%) which were conducted in American and Indian populations, respectively (Table 2 ).

Parietal foramen located on the sagittal suture has been termed median PF [7]. The present study revealed a $5 \%$ incidence of the median PF (Table 2), of which $1 \%$ had only the median foramen present (Fig. 2A), 2\% had the median foramen present along with a unilateral PF (Fig. 2B), and $2 \%$ had the median foramen present with bilateral PF (Fig. 2C). This type of foramen was reported by Keskil et al. [9] (5\%) and Mann et al. [11] (0.7\%) which were conducted in Turkish and Japanese populations, respectively (Table 2). The weighted mean incidence of the median PF in the literature is $3.4 \%$ (Table 2).

Determining the topography of the foramen in relation to the sagittal suture is clinically important for neurosurgical techniques due to the risk of rupture of emissary veins during surgical procedures $[14,16]$. The present study has a similar range, $4.44-18.20 \mathrm{~mm}$, of the location of the PF from the sagittal suture when compared to previous studies such as Yoshioko et al. [20] and Murlimanju et al. [14] which reported ranges of 3.00$-12.00 \mathrm{~mm}$ and $0.50-15.00 \mathrm{~mm}$, respectively (Table 3). However, the mean distance reported by the present 
study, $9.02 \mathrm{~mm}$, was found to be higher in comparison to previous studies such as Halagatti and Sagar [8] and Shantharam and Manjunath [16] who reported mean distances of $6.60 \mathrm{~mm}$ and $7.34 \mathrm{~mm}$, respectively (Table 3).

Information on skull foraminal size is imperative due to radiological advancements by use of magnetic resonance imaging and computed tomography to make diagnoses of pathological conditions $[2,16]$. With respect to diameter, the range of $0.74-3.08 \mathrm{~mm}$, recorded in the present study is similar to that of studies conducted by Yoshioko et al. [20] (0.40$-4.30 \mathrm{~mm}$ ) and Shantharam and Manyjunath [16] $(0.86-5.57 \mathrm{~mm})$, respectively; however, this range was greater than that of Mann et al. [11] (1.80-2.00 mm) (Table 4). The mean diameter reported by present study, $1.55 \mathrm{~mm}$, was found to be lower than that of Yoshioko et al. [20] (1.80 mm), yet higher than studies conducted by Berge and Bergman [2] $(0.67 \mathrm{~mm})$ and Singh and Raibagkar [17] (0.91 mm) (Table 4).

Shantharam and Manjunath [16] stated that perhaps differences in studies conducted by Yoshioko et al. [20] and Boyd [4] were due to racial differences. Furthermore, Berry and Berry [3], in a study of variations of the human cranium, stated that the frequency of any particular variant is consistent in any given race. Thus, a need for population specific data of the anatomical parameters of the PF has been highlighted; therefore, the present study aimed to partially fill this gap since a thorough review of the literature has revealed the paucity of data regarding the PF within a South African population.

Variations of skull foramina are important for their disease associations and surgical implications $[12,17]$. Therefore, due to the high incidence of the PF as reported by the present study, and since the emissary veins of the cranium will be encountered by the neurosurgeon, knowledge of the anatomy of the emissary PF is imperative.

\section{Conflict of interest: None declared}

\section{REFERENCES}

1. Agarwal $P$, Baranwal $S$, Pandey $M$, et al. Large midline persistent parietal foramina with occipital encephalocele and abnormal venous drainage. JCLPA. 2015; 2(1): 66-69, doi: 10.4103/2348-2125.150757.

2. Berge JK, Bergman RA. Variations in size and in symmetry of foramina of the human skull. Clin Anat. 2001; 14(6): 406-413, doi: 10.1002/ca.1075, indexed in Pubmed: 11754234 .
3. Berry AC, Berry RJ. Epigenetic variation in the human cranium. J Anat. 1967; 101(Pt 2): 361-379, indexed in Pubmed: 4227311.

4. Boyd Gl. The emissary foramina of the cranium in man and the anthropoids. J Anat. 1930; 65(Pt 1): 108-121, indexed in Pubmed: 17104299.

5. Collipal E, Silva H, Quintas F, et al. Morphometry study of the parietal foramen. Int J Morphol. 2009; 27: 481-484.

6. Debbarma S, Zaidi SHH, Mishra A, et al. A study of parietal foramen in North Indian population. JMS. 2015; 5(2): 143-145.

7. Gangmei G, Devi HS, Daimei T, et al. Variations of parietal foramen in dried adult human skulls. IOSR-JDMS. 2018: 26-29.

8. Halagatti M, Sagar S. An anatomical study of parietal emissary foramina in dry adult human skulls. IJARS. 2018: 20.

9. Keskil S, Gözil R, Calgüner E. Common surgical pitfalls in the skull. Surg Neurol. 2003; 59(3): 228-231, doi: 10.1016/ s0090-3019(02)01038-8, indexed in Pubmed: 12681561.

10. Makandar UK, Kulkarni PR, Suryakar AN. Comparative study of incidence of parietal foramina in north and south indian human crania. Indian J Forensic Med Toxicol. 2013; 7(2): 123-127, doi: 10.5958/j.0973-9130.7.2.027.

11. Mann R, Manabe J, Byrd J. Relationship of the Parietal Foramen and Complexity of the Human Sagittal Suture. Int J Morphol. 2009; 27(2), doi: 10.4067/s071795022009000200040.

12. Mortazavi MM, Tubbs RS, Riech S, et al. Anatomy and pathology of the cranial emissary veins: a review with surgical implications. Neurosurgery. 2012; 70(5): 1312-8; discussion 1318, doi: 10.1227/NEU.0b013e31824388f8, indexed in Pubmed: 22127046.

13. Moore KL, Dalley AF. Clinically Oriented Anatomy, 5th Ed. Lippincott Williams \& Wilkins, Philadelphia 2006: 897.

14. Murlimanju BV, Saralaya VV, Somesh MS, et al. Morphology and topography of the parietal emissary foramina in South Indians: an anatomical study. Anat Cell Biol. 2015; 48(4): 292-298, doi: 10.5115/acb.2015.48.4.292, indexed in Pubmed: 26770881.

15. Pereira GA, Lopes PT, Santos AM, et al. Study of landmarks in dried skulls in a Brazil population. J Morphol Sci. 2013; 30(2): 94-97.

16. Shantharam $V$, Manjunath $K Y$. Anatomical study of parietal emissary foramina in human skulls. IJARS. 2018; 7(1): A011-A014.

17. Singh PR, Raibagkar CJ. Study of variation in atypical foramina of dry human skull. NJIRM. 2011; 2(2): 1-5.

18. Wysocki J, Reymond J, Skarzyński H, et al. The size of selected human skull foramina in relation to skull capacity. Folia Morphol. 2006; 65(4): 301-308, indexed in Pubmed: 17171609.

19. Yılmaz E, Yetim A, Erol OB, et al. Multiple occipital, parietal, temporal, and frontal foramina: a variant of enlarged parietal foramina in an infant. Balkan Med J. 2014; 31(4): 345-348, doi: 10.5152/balkanmedj.2014.14528, indexed in Pubmed: 25667790.

20. Yoshioko N, Rhoton AL, Abe H. Scalp to meningeal arterial anastomosis in the parietal foramen. Neurosurgery. 2006; 58(1 Suppl): ONS123-ONS126, doi: 10.1227/01. NEU.0000193516.46104.27, indexed in Pubmed: 16543869 . 